\title{
Neonatal Isolation Stress Potentiates Cocaine Seeking Behavior in Adult Male and Female Rats
}

\author{
Wendy J Lynch*', Lauren D Mangini' and Jane R Taylor' \\ 'Department of Psychiatry, Yale University, New Haven, CT, USA
}

\begin{abstract}
Little is known with regard to how sex and stress might interact as vulnerability factors in cocaine abuse. In this study, we compared the effects of neonatal isolation stress on cocaine self-administration under extended access conditions and on subsequent responding in a cue-induced reinstatement paradigm in adult male and female rats. Pups from each litter were subjected to either neonatal isolation ( I h/ day) or brief daily handling from postnatal day 2 through 12. Adults rats were then trained to self-administer cocaine, and once they acquired lever responding for cocaine under a fixed ratio I schedule, they were given 24-h access to intravenous cocaine infusions $(1.5 \mathrm{mg} / \mathrm{kg})$ that were available in discrete trials $(4,10 \mathrm{~min}$ trials $/ \mathrm{h})$ for 7 consecutive days. At 10 days after the last discrete trial session, responding was assessed during six to eight I-h extinction sessions that were followed by a I-h cue-induced reinstatement session. Results revealed that females took more cocaine than did males over the 7-day discrete trial self-administration period and tended to respond at higher levels during the initial extinction sessions. Although intake did not differ between handled control rats and isolated rats under extended access conditions, stress effects were observed under subsequent extinction and cue-induced reinstatement testing conditions with isolated rats responding at higher levels during both phases. Notably, stress seemed to obscure sex differences in extinction responding such both isolated males and females responded at high levels. These findings demonstrate robust and enduring effects of neonatal isolation stress on cocaine seeking behavior in adult male and female rats.

Neuropsychopharmacology (2005) 30, 322-329, advance online publication, 27 October 2004; doi: I 0. I 038/sj.npp. I 300594
\end{abstract}

Keywords: addiction; cocaine; reinstatement; self-administration; sex differences; stress

\section{INTRODUCTION}

Studies with both humans and laboratory animals demonstrate that sex can be an important vulnerability factor for cocaine abuse. Although the rates of drug abuse are lower in women than in men (Substance Abuse and Mental Health Services Administration, 2001), recent evidence suggests that women may be more vulnerable than men to some aspects of cocaine abuse. For example, women initiate cocaine use sooner, have more emergency room visits following crack use, and report a greater nervousness following intranasal cocaine than do men (for reviews see Lynch et al, 2002; Mello and Mendelson, 2002). The course or progression to dependence may also differ between men and women. It has often been suggested in the alcohol literature that women progress through the landmark stages to dependence at a faster time course than men (Brady and Randall, 1999). This has been termed telescoping and

*Correspondence: WJ Lynch, Department of Psychiatry, Yale University School of Medicine, 34 Park St, New Haven, CT 06516, USA, Tel: + I 203974 7755, Fax: + I 203974 7897,

E-mail: wendy.lynch@yale.edu

Received 18 May 2004; revised 9 September 2004; accepted 17 September 2004

Online publication: 22 September 2004 at http://www.acnp.org/citations/ Npp092204040230/default.pdf reflects a shorter time course for the development of medical consequences and behavioral/psychological factors characteristic of an alcohol dependence disorder. Similar suggestions have been proposed for cocaine abuse (Kosten et al, 1996). Additionally, although cocaine-addicted women and men typically report similar levels of cocaine use (Evans et al, 1999), women are more likely than men to report craving following exposure to cocaine-related cues (Robbins et al, 1999), suggesting that during abstinence, women may be more motivated than men to use cocaine (Elman et al, 2001).

Similar results have been reported with laboratory animals. For example, female rodents display more robust locomotor sensitization, greater rotational and stereotypic behavior, and greater increases in locomotor activity in response to cocaine compared to male rodents (Haney et al, 1994; Hu and Becker, 2003; Chin et al, 2001, 2002; Glick and Hinds, 1984; Forgie and Stewart, 1993, 1994; Camp et al, 1986). Sex differences have also been observed for cocaine self-administration behavior during several different phases. For example, under low dose conditions, female rats acquire cocaine self-administration at a faster rate than do male rats (Lynch and Carroll, 1999; Carroll et al, 2002; $\mathrm{Hu}$ et al, 2004), but once they have acquired, like humans, male and female laboratory animals typically do not differ in maintenance levels of cocaine intake (Lynch and Carroll, 
1999; Roberts et al, 1989; Caine et al, 2004). Females do, however, respond at higher levels under a progressive ratio schedule during the maintenance phase, suggesting that females are more motivated to obtain cocaine during this phase (Roberts et al, 1989). Females also respond at higher levels under cocaine-induced reinstatement testing conditions (Lynch and Carroll, 2000). Additionally, we have recently compared male and female rats under extended access conditions using a discrete trial procedure $(4$ trials $/ \mathrm{h}$, $1.5 \mathrm{mg} / \mathrm{kg}$ ) and found that females take more cocaine over a 7-day access period, and following a 10-day forced abstinence period, females are more motivated to obtain cocaine infusions than are males (Lynch and Taylor, 2004). These findings may reflect compulsive aspects of addiction and they suggest that females may have a greater biological vulnerability to cocaine abuse than do males.

An additional factor that may predict a vulnerability to cocaine abuse is stress. Results from humans have shown that both psychological and physical stressors elicit craving for cocaine often to a similar degree as cocaine cues (Sinha et al, 1999, 2000, 2003). Additionally, numerous human studies have reported a positive association between adverse life events, chronic stress/distress, and increased risk to drug abuse (for a review see Sinha, 2001), suggesting that stress may contribute to not only an increased vulnerability to relapse to drug use during periods of abstinence but also to the development and maintenance of compulsive drug use (Coffey et al, 2002; Sinha, 2001). In laboratory animals, a wide variety of stressors also have been shown to enhance cocaine and/or amphetamine selfadministration including foot shock (Goeders and Guerin, 1994, 1996; Erb et al, 1998), tail pinch (Piazza et al, 1990), food deprivation (Campbell and Carroll, 2001; Carroll et al, 1981, 1986; Shalev et al, 2003; Comer et al, 1995), social isolation (Howes et al, 2000; Schenk et al, 1987), and aggressive threat of attack (Tidey and Miczek, 1997; Haney et al, 1995). Although most of these studies have focused on the acquisition or reinstatement phases, similar results have been reported during the maintenance phase (for reviews see Goeders, 2002; Lu et al, 2003).

Recent work has shown that stress can also be a predictive factor of drug use vulnerability even if the source of the stress is not extant at the time of greatest risk for relapse (Haney et al, 1995; Covington and Miczek, 2001; Matthews et al, 1999; Kosten et al, 2000, 2004; Schenk et al, 1987). For example, neonatal isolation stress has been reported to produce physiological and neurochemical changes that persist into adulthood and disrupt certain behaviors, including cocaine self-administration behavior (Matthews et al, 1999; Kosten et al, 2000, 2004). As little as $1 \mathrm{~h}$ per day away from its mother and siblings for the second through the ninth postnatal day can have lifelong consequences for a rat pup (McCormick et al, 1998, 2002; Kosten et al, 2000, 2004; Kehoe and Bronzino, 1999). For example, neonatal isolation stress has been reported to increase rates of acquisition of cocaine self-administration behavior in adult male and females rats (Kosten et al, 2000, 2004). However, the effect of stress and its interaction with sex during other phases of the addiction process is not known. Thus, the objectives of these studies was to examine possible interactions of sex and stress on vulnerability to cocaine using self-administration procedures that capture aspects that are critical for human cocaine abuse, namely high levels of use and a propensity to relapse (APA, 1994; Jentsch and Taylor, 1999).

\section{METHODS}

\section{Subjects}

Litters born to 12 Sprague-Dawley rats were sexed and culled to eight pups per litter, four females and four males each (except one litter with two females and six males), on postnatal day 1. Each dam and her litter were housed in a plastic cage with free access to food and water, and animals were maintained on a 12-h light/dark cycle (lights on at 0700) for the entire experiment. After postnatal day 12, all animals were left without handling until weaning on postnatal day 25 (except for periodic cage cleaning), when pups were weighed, marked, and caged in same-sex pairs. At approximately 65 days of age, all animals were housed individually. At approximately 90 days of age, each rat was anesthetized with a mixture of pentobarbital $(4 \mathrm{mg} / \mathrm{kg}$, i.p.) and chloral hydrate $(20 \mathrm{mg} / \mathrm{kg}$, i.p.) and implanted with a chronic indwelling cannula into the right jugular vein using methods that have been described previously (Lynch and Carroll, 2000). After cannulation, the rats were placed in individual operant chambers (ENV-018M; Med Associates, St Albans, VT), and once grooming and eating behaviors resumed, behavioral testing began (typically after 24-h of recovery). Rats were weighed a minimum of once per week, and immediately prior to and following 24-h access to cocaine under the discrete trial procedure. In order to control for the stress of handling, animals were not weighed during the 7-day period in which cocaine was available under the 24-h/day discrete trial procedure. Cannula patency was assessed approximately every 7 days, and if a cannula was not patent a new one was implanted into the left jugular vein and testing resumed a minimum of 24-h later. The health of the animals was monitored daily. The experimental protocol was approved by the Animal Care and Use Committee of Yale University and was conducted in accordance with guidelines set by the National Institutes of Health.

\section{Drugs}

Cocaine hydrochloride was purchased from Sigma Chemical Company (St Louis, MO), and dosages are expressed as the salt. Cocaine was mixed in sterile $0.9 \%$ saline and passed through a micro-filter. Cocaine infusions $(1.5 \mathrm{mg} / \mathrm{kg})$ were delivered at a rate of $0.024 \mathrm{ml} / \mathrm{s}$ and the infusion duration was adjusted according to the body weight of each subject $(1.5 \mathrm{~s} / 100 \mathrm{~g})$. A relatively high dose of cocaine was tested in these experiments $(1.5 \mathrm{mg} / \mathrm{kg})$. This dose was selected based on previous work showing under extended access conditions using the discrete trial procedure, this dose of cocaine maintained high levels of use and dysregulated patterns of intake, particularly in female compared to male rats (Lynch and Taylor, 2004).

\section{Experimental Procedures}

Neonatal isolation. The neonatal isolation procedure that was used has been described previously and has been shown 
to produce long-lasting physiological and behavioral effects (McCormick et al, 1998, 2002; Kosten et al, 2000, 2004; Kehoe and Bronzino, 1999). This procedure began on postnatal day 2. Half of the litters were randomly assigned to the neonatal isolation condition, and the other half were assigned to the handling-only control condition. In the isolated condition, each pup was removed from the dam and placed in an individual glass jar with bedding. The jars were set in a plastic container filled with heated water to maintain an appropriate body temperature $\left(32-34^{\circ} \mathrm{C}\right)$ in the pups. The plastic containers were placed in a heat and humidity controlled room, and the pups remained in this environment for $1 \mathrm{~h}$ per day. This procedure was carried out daily from postnatal day 2 through 12 between 0900 and $1200 \mathrm{~h}$. The control animals were briefly handled (30 s) each day to control for the handling experienced by the isolated animals.

Cocaine self-administration training. In order to control for possible dam effects, each group (isolated and handled controls) was composed of rats derived from six different litters. Rats were initially trained to self-administer a high dose of cocaine under a fixed ratio 1 schedule in order to ensure that all animals acquired cocaine self-administration. Specifically, after a minimum of 1 day recovery from surgery, the rats were allowed to self-administer cocaine infusions $(1.5 \mathrm{mg} / \mathrm{kg})$ during daily sessions beginning at 2400 hours. At the beginning of each training session, the left lever (cocaine-associated lever) was extended into operant chamber and each response on it produced an infusion of cocaine, and the stimulus light about the lever was illuminated for the duration of the infusion (approximately $5 \mathrm{~s}$ ). Each rat received one 'priming' infusion at the beginning of each training session. The left lever remained extended into the chamber and cocaine infusions were available until a total of 20 injections were obtained. Rats generally began self-administering cocaine at the start of each daily session (2400 hours) and obtained all 20 infusions in approximately $3 \mathrm{~h}$ (1500 hours). The right lever (activity lever) was extended into the chamber for the duration of the experiment, and responses on it were recorded but produced no consequence. Responding was assessed daily under the fixed-ratio schedule until rats met criteria for acquisition. Acquisition of cocaine self-administration was defined as five consecutive sessions in which rats earned all 20 infusions that were available.

Cocaine self-administration under a 24-h access discrete trial procedure. Once rats acquired cocaine self-administration under a fixed-ratio schedule, responding was assessed for seven consecutive sessions under a 24-h discrete trial procedure (Roberts et al, 2002; Lynch and Roberts, 2004; Lynch and Taylor, 2004) to determine whether isolated males $(n=12)$ and females $(n=12)$ differed from handled control males $(n=13)$ and females $(n=12)$ on patterns and levels of intake under extended access conditions. However, over the course of the 7 day 24$h$ access discrete trial procedure, signs of toxicity (eg rapid weight loss, death) were apparent in two out of the 12 isolated females rats tested, one out of the 12 isolated males tested, and one out of the 12 handled control females tested.
These animals were removed from the study and their data were not included in the final analyses. Trials were initiated every 15-min for a total of 7 days. Each 10-min trial began with the introduction of the left lever into the chamber. Each response on this lever during a 10-min trial produced an infusion of cocaine $(1.5 \mathrm{mg} / \mathrm{kg} /$ infusion $)$, and the stimulus light above the lever was illuminated for the duration of the infusion (approximately $5 \mathrm{~s}$ ). A discrete trial was terminated and the lever was retracted following a response under a fixed-ratio 1 schedule or after 10-min had elapsed.

Extinction and cue-induced reinstatement following a 10-day forced abstinence period. In order to examine the effects of sex and stress on drug-seeking behavior following extended access to cocaine, isolated males $(N=11)$ and females $(N=10)$ and handled control males $(N=13)$ and females $(N=10)$ were tested under a cue-induced reinstatement procedure. Data from one of the original 11 handled control females was not included due to equipment failure. Following the last 24-h discrete trial session under the discrete trial procedure, rats were removed from the operant testing chambers and individually housed in a colony room in order to make more efficient use of the operant testing chambers. Rats remained in these boxes for 10 days. At 10 days after the last discrete trial cocaine selfadministration session, animals were re-housed in operant test chambers, and responding was examined under an extinction/cue-induced reinstatement paradigm. This time point was selected based on previous findings with male rats, showing that cue-induced reinstatement responding was significantly increased from baseline at this time point (Grimm et al, 2001) and from recent results from our laboratory showing that females are highly motivated to obtain cocaine infusions following a 10-day forced cocaine abstinence period (Lynch and Taylor, 2004). Extinction responding was assessed in 6-8, 1-h sessions. Each 1-h extinction session was initiated by the introduction of the previously active lever and the illumination of the house light. The stimulus light and the sound of the pump, two discrete cues associated with availability of the drug, were not present during these sessions. At the end of each session, the house light was turned off and the lever retracted. All animals were given a minimum of six, 1-h extinction sessions separated by $5 \mathrm{~min}$ until they reached the extinction criterion of fewer than 15 responses per hour on the previously active lever (approximately seven sessions).

The cue-induced reinstatement procedure was a 1-h session beginning $5 \mathrm{~min}$ after the last extinction session. With this procedure, the discrete cues that were formerly associated with cocaine (eg sound of pump activation and stimulus light above active lever) function as conditioned reinforcers and serve to reinstate lever press responding (ie Grimm et al, 2001). At the beginning of the cue-induced reinstatement session, one noncontingent presentation of the cues formerly associated with cocaine (sound of pump activation and stimulus light above active lever) was given at the beginning of this session. During this session, responses on the previously active lever led to the presentation of the stimulus light and sound of the pump cues on a fixed-ratio 1 schedule. 


\section{Data Analysis}

The mean number of days to acquire cocaine selfadministration and mean daily cocaine intake over the 7day period in which cocaine was avaiable under the 24 -h discrete trial procedure were compared between males and females and isolated and handled control groups using separate two-factor ANOVAs. The total number of responses made during the first six 1-h extinction sessions was compared between groups using repeated measures ANOVA. The total number of responses made during the 1-h cue-induced reinstatement session was compared to the number of responses made during the last 1-h extinction session and between groups using repeated measures ANOVA with stress and sex as the between-subject factors and cue (no cue versus cue) as the within-subject factor. $p$-Values equal to or less than 0.05 were considered statistically significant.

\section{RESULTS}

\section{Cocaine Self-Administration under a 24-h Access Discrete Trial Procedure}

Figure 1 shows mean daily cocaine intake observed under the 24-h access discrete trial procedure for male and female handled control and isolated rats. Females self-administered more cocaine than did males over the 7 days, and this effect was particularly apparent within the handled control animals. Compared to handled controls, isolated rats selfadministered only approximately $2 \%$ more cocaine $(-3 \%$ for females and $7 \%$ for males). A two-way ANOVA revealed a significant overall effect of $\operatorname{sex}(\mathrm{F}(1,41)=5.52, p<0.05)$, but nonsignificant effects of stress $(p>0.05)$ and the interaction of stress and sex $(p>0.05)$. Thus, females selfadministered more cocaine than did males, but there was no significant effect of stress on intake.

Under these extended access conditions signs of cocaine toxicity were apparent in only a few of the total animals tested. Specifically, of the 24 females tested, three died or

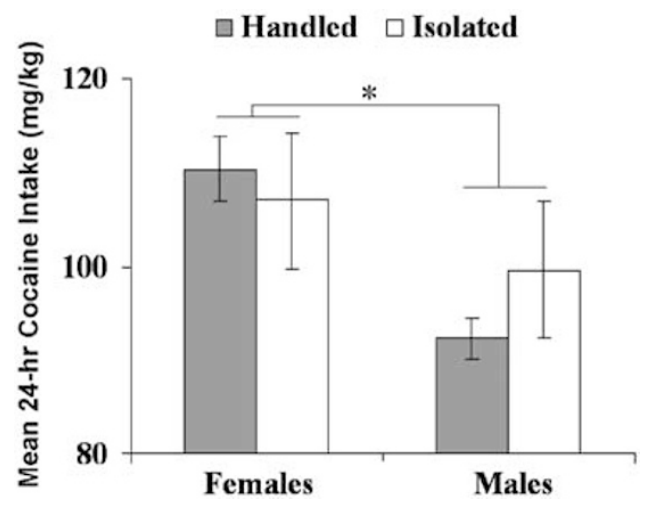

Figure I Effect of stress on levels of cocaine self-administration under a $24-h$ access discrete trial procedure in male and female rats. Mean $( \pm S E)$ daily intake averaged across the 7 days of access under the discrete trial procedure for handled control and isolated male and female rats. Each data point represents the mean of $11,10,13,11$ rats for the handled control females, isolated females, handled control males, and isolated males, respectively. The asterisk indicates a significant difference between males and females $(p<0.05)$. showed rapid weight loss over the course of the 7-day 24-h access discrete trial procedure. Of the 25 males tested, one died over the course of the 7-day 24-h access discrete trial procedure. Moderate weight loss was observed in all groups tested. Specifically, compared to the body weights observed prior to 24-h access to cocaine under the discrete trial procedure, the body weights observed immediately following discrete trial cocaine self-administration were decreased by an average of $10.5 \%( \pm 2.6)$ in isolated females, $11.9 \%$ $( \pm 1.5)$ in isolated males, $10.8 \%( \pm 2.5)$ in handled control females, and $12.7( \pm 1.5)$ in handled control males. A twofactor ANOVA on percent change in body weight revealed a nonsignificant effect of stress, sex, and the interaction of sex by stress ( $p$ 's $>0.05)$. Thus, all groups lost a similar amount of weight under these extended access conditions and few signs of toxicity were observed.

\section{Extinction and Cue-Induced Reinstatement Following a 10-Day Forced Abstinence Period}

Figure 2 illustrates the effects of sex and stress on extinction responding. Responding extinguished (defined as fewer than 15 responses during a $1-\mathrm{h}$ session) for all animals within a maximum of 8,1 -h sessions, and the mean number of sessions to reach this extinction criteria was approximately 7 and did not significantly differ between groups $(p>0.05)$. The greatest levels of responding were observed within the first two 1-h extinction sessions and thereafter
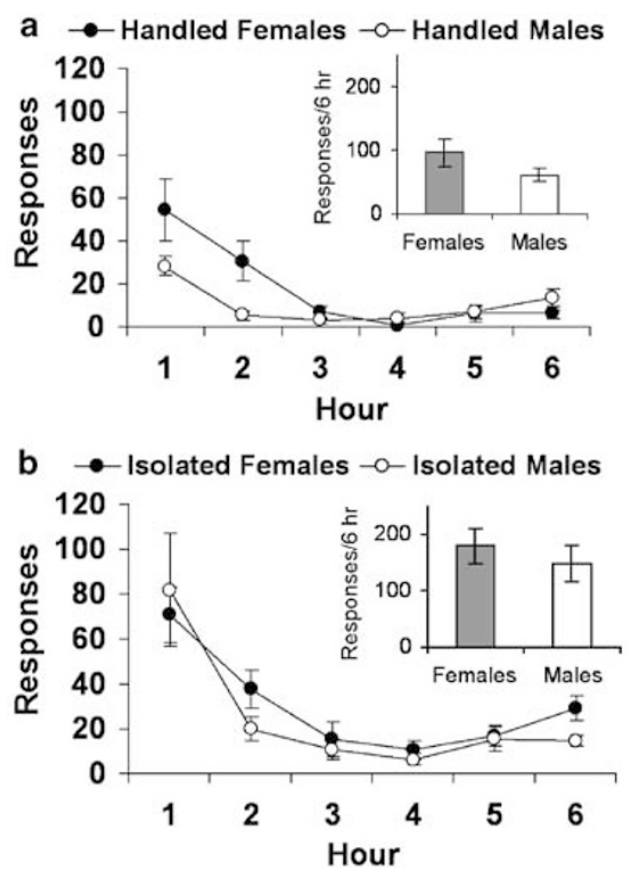

Figure 2 Effect of stress on extinction responding following a 10-day forced abstinence period. (a) Mean $( \pm \mathrm{SE}$ ) total levels of responding as a function of hour during the first six I-h extinction sessions for handled control females $(n=10)$ and males $(n=13)$. The inset shows the mean $( \pm \mathrm{SE})$ total number of responses averaged across the six, I-h extinction sessions. (b) Mean ( \pm SE) total levels of responding as a function of hour during the first six $1-h$ extinction sessions for isolated females $(n=10)$ and males $(n=||)$. The inset shows the mean $( \pm S E)$ total number of responses averaged across the six, I-h extinction sessions. 
responding showed a progressive decline. Females tended to respond at higher levels during the initial extinction sessions than did males, particularly among handled controls (Figure 2a). Isolated rats responded at much higher levels under the extinction testing sessions compared with handled control rats, particularly within the first two extinction sessions (compare Figure $2 \mathrm{a}$ and $\mathrm{b}$ ). Compared to handled controls, isolated rats responded approximately $52 \%$ more under extinction testing conditions ( $42 \%$ for females and $62 \%$ for males; see insets). A two-factor repeated measures ANOVA revealed significant main effects of stress $(\mathrm{F}(1,40)=11.42, p<0.01)$ and time $(\mathrm{F}(5,200)=31.26, p<0.0001)$, a significant interaction of time by stress $(F(5,200)=2.33, p<0.05)$, and a trend for a significant interaction of time by stress by sex (F $(5,200)=1.95, p=0.08)$. Thus, handled control females tended to respond at higher levels under the initial extinction sessions compared to handled control males and isolated rats responded at higher levels under extinction testing conditions compared to handled control rats.

Similarly, under cue-induced reinstatement testing conditions, isolated rats responded at much higher levels than did handled control rats (Figure 3). Isolated rats responded approximately $48 \%$ more under cue-induced reinstatement testing conditions than did handled control rats (44\% for females and $53 \%$ for males). A repeated measures ANOVA comparing levels of responding under the cue reinstatement session relative to levels of responding under the last extinction session revealed a significant main effect of stress $(\mathrm{F}(1,40)=10.4, p<0.01)$ and cue $(\mathrm{F}(1,40)=85.5, p<0.001)$ and a significant interaction of cue by stress $(\mathrm{F}(1,40)=11.4$, $p<0.01)$, but nonsignificant effects of sex $(p>0.05)$ and all interactions of sex ( $p$ 's $>0.05)$. These data demonstrate that neonatal isolation similarly enhanced cue-induced reinstatement responding in both male and female rats.

\section{DISCUSSION}

The goal of this study was to investigate interactions between sex and stress on levels of cocaine intake under

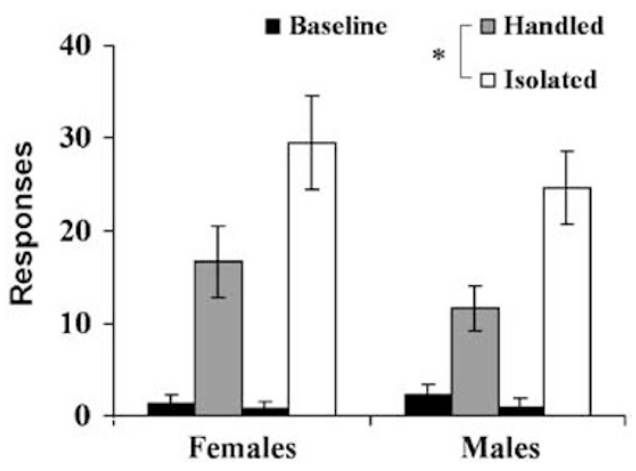

Figure 3 Effect of stress on cue-induced reinstatement following a 10day forced abstinence period. Mean ( \pm SE) total levels of responding during the I-h cue-induced reinstatement session for handled control females $(n=10)$, isolated females $(n=10)$, handled control males $(n=13)$, and isolated males $(n=I \mathrm{I})$. The black bars (Baseline) show the mean $( \pm \mathrm{SE})$ number of responses during the last I-h extinction for each of the groups. The asterisk indicates a significant difference between handled control rats and isolated rats $(p<0.0 \mathrm{l})$. extended access conditions and on cue-induced reinstatement after such access. Under extended access conditions, females self-administered more cocaine than did males, but no effect of stress was observed. Stress effects were observed under extinction and cue-induced reinstatement testing conditions with isolated rats responding at higher levels compared to handled controls. Additionally, under extinction testing conditions, female handled controls tended to respond at higher levels during the initial extinction sessions compared to male handled controls, an effect that was obscured by neonatal isolation stress. Taken together, these findings demonstrate that both sex and stress alter vulnerability to cocaine self-administration during different phases of the addiction process.

\section{Sex Differences}

We have previously reported that under 24-h access conditions using a discrete trial procedure females take more cocaine over a 7-day testing period (Lynch and Taylor, 2004). Here, we replicate this previous finding and extend it to include sex differences during extinction following such access conditions. Compared to handled control males, females tended to respond at higher levels, particularly during the initial extinction sessions. This finding is consistent with our previous work showing that females respond at higher levels under extinction testing conditions (Lynch and Carroll, 2000) and our recent finding showing that following a 10-day forced abstinence period, females were more motivated to obtain cocaine infusions as measured by responding under a progressive-ratio schedule (Lynch and Taylor, 2004). The lack of a sex difference under the cue-induced reinstatement testing conditions contrasts to our previous work showing that under a priming model of reinstatement, females respond on the lever formerly associated with cocaine at much higher levels than do males (Lynch and Carroll, 2000). This raises the possibility that sex differences during reinstatement may be relevant following internal cues (ie priming doses of cocaine), but not following secondary, external drug cues. Further work is necessary to determine the conditions necessary to produce reinstatement in male and female rats (eg cue-, cocaine-, and stress-induced reinstatement).

\section{Effect of Stress}

The present results showed that isolated rats responded at higher levels under extinction and cue-induced reinstatement conditions and acquired cocaine self-administration at a faster rate under high dose fixed ratio training conditions compared to handled control rats. These findings are consistent with previous work showing that stress is a vulnerability factor that affects cocaine selfadministration behavior during the different phases of cocaine abuse including acquisition, maintenance, and reinstatement (eg Goeders, 2002; Lu et al, 2003), and they extend previous findings of stress as a vulnerability factor to include cocaine seeking behavior following extended access conditions. Additionally, these findings are consistent with previous work using a similar neonatal isolation procedure showing that neonatal isolation stress has enduring and 
robust effects on acquisition of cocaine self-administration in both male and female rats (Kosten et al, 2000, 2004).

In contrast to the present results showing that neonatal isolation potentiates cocaine seeking behavior and previous findings that neonatal isolation stress enhances cocaine selfadministration (Kosten et al, 2000, 2004), Matthews et al (1999) reported that $1 \mathrm{~h} /$ day of neonatal maternal separation had no effect, or attenuated, acquisition of cocaine selfadministration, particularly in female rats. Procedural differences between the neonatal maternal separation and the neonatal isolation procedure may explain this discrepancy. Specifically, with the maternal separation paradigm pups are separated from the dam and housed by litter, whereas, with the isolation paradigm pups are isolated from both the dam and their littermates. Numerous studies have investigated the effects of maternal separation on physiological changes, particularly with regard to HPA axis function. Results from these studies have shown that extended periods of separation (eg $24 \mathrm{~h}$ ) were necessary to produce robust and enduring changes in HPA function (Schmidt et al, 2004; Levine, 2002; Rots et al, 1996). In contrast, McCormick et al (1998) reported that rats that were isolated from mother and siblings for only $1 \mathrm{~h} /$ day from postnatal day 2 through 9 showed increased plasma corticosterone levels, much higher than normal corticosterone levels in control animals. This abnormal hyperactivation of the hypothalamic-pituitary-adrenal (HPA) axis demonstrates prolonged stress in the animal, and can affect later development (McCormick et al, 1998). Previous work (McCormick et al, 2002) and unpublished results from our laboratory have shown that although basal levels of corticosterone decrease to normal levels by adulthood, juvenile rats that were neonatally isolated show a heightened corticosterone in response to an acute stressor (McCormick et al, 2002), a finding that has been hypothesized to predict an increased vulnerability to cocaine self-administration (Marinelli and Piazza, 2002).

These data also suggest that stress may obscure sex differences in cocaine seeking behavior. Specifically, consistent with our previous findings (Lynch and Carroll, 2000), handled control female rats in the present study tended to respond at higher levels than did handled control female rats under extinction testing conditions. However, isolated male rats, like female rats, responded at high levels under extinction testing conditions and they did not appear to differ from females in hourly levels of responding across the 6-h extinction sessions. This finding suggests that the effect of stress on extinction behavior may be more pronounced in males than females possibly due to a ceiling effect in females.

It should be noted that handling during the neonatal period has also been shown to lead to changes in the HPA axis function and responsivity to stress that could potentially impact cocaine self-administration behavior. Specifically, previous work has shown that handling pups during the neonatal isolation period protects the animals from stress in adulthood (relative to a nonhandled group; for a review see Meaney et al, 1991), and thus would be predicted to reduce vulnerability to cocaine self-administration. However, in these previous studies, the handled groups were held and/or stroked for much longer periods of time than those used in the present study (eg typically
15 min or more compared to only approximately $30 \mathrm{~s}$ in the present study). Even still, we cannot rule out the possibility that differences between the handled control rats and the isolated rats might be due to changes in the handled control rats rather than due to the effects of neonatal isolation stress. However, this possibility seems unlikely given that our results are consistent with previous research on acquisition of cocaine self-administration in which isolated rats were compared with a nonhandled control group (Kosten et al, 2000, 2004). Further support for the idea that neonatal isolation stress, rather than brief handling, potentiated cocaine seeking behavior in the present study is provided by previous findings showing that although briefly handled and nonhandled rats differed from isolated rats on several physiological and behavioral measures, little, if any, differences were noted between briefly handled and nonhandled rats (McCormick et al, 1998; Kehoe et al, 1998).

\section{CONCLUSION}

These data demonstrate that neonatal isolation stress potentiates cocaine seeking behavior following extended access to cocaine in both male and female rats. The effects of neonatal isolation stress were robust and, notably, endured well into adulthood. The effect of stress appeared to be equally, if not more effective in males than females, and under extinction testing conditions, obscured baseline sex differences in levels of responding bringing the males up to the females level. Although it is not precisely known what mediates sex differences in the various phases of drug selfadministration behavior, one strong possibility is ovarian hormones. Previous work has shown that estrogen, in particular, plays a critical role in modulating the behavioral and reinforcing effects of cocaine in both women (Sofuoglu et al, 1999) and female laboratory animals (Hu and Becker, 2003; Lynch et al, 2001, 2000; Roberts et al, 1989; Sircar and Kim, 1999; Sell et al, 2000; Walker et al, 2001a). Notably, both sex and stress have been reported to modulate hypothalamic/pituitary/adrenal function (Kuhn and Francis, 1997; Walker et al, 2001a, b), an important predictor of vulnerability to cocaine self-administration. Further work is necessary to determine mechanisms underlying the effects of sex and stress during different phases of addiction process.

\section{ACKNOWLEDGEMENTS}

We are grateful to Jessica Johnson for her technical assistance and to Dr Rajita Sinha for her critical comments on a previous version of this manuscript. We would like to acknowledge the Yale Interdisciplinary Women's Health Research Scholar Program on Women and Drug Abuse, NIH Office of Research on Women's Health. This work was supported by NIDA grants DA11717, DA016556, and DA114038.

\section{REFERENCES}

American Psychiatric Association (1994). Diagnostic and Statistical Manual of Mental Disorders, 4th edn. American Psychiatric Press: Washington, DC. 
Brady KT, Randall CL (1999). Gender differences in substance use disorders. Psychiatr Clin N Am 22: 241-252.

Caine SB, Bowen CA, Yu G, Zuzga D, Negus SS, Mello NK (2004). Effect of gonadectomy and gonadal hormone replacement on cocaine self-administration in female and male rats. Neuropsychopharmacology 29: 929-942.

Camp DM, Becker JB, Robinson TE (1986). Sex differences in the effects of gonadectomy on amphetamine-induced rotational behavior in rats. Behav Neural Biol 46: 491-495.

Campbell UC, Carroll ME (2001). Effects of ketoconazole on the acquisition of intravenous cocaine self-administration under different feeding conditions in rats. Psychopharmacology 154: 311-318.

Carroll ME, France CP, Meisch RA (1981). Intravenous selfadministration of etonitazene, cocaine and phencyclidine in rats during food deprivation and satiation. J Pharmacol Exp Ther 217: 241-247.

Carroll ME, Lac ST, Walker MJ, Kragh R, Newman T (1986). Effects of naltrexone on intravenous cocaine self-administration in rats during food satiation and deprivation. J Pharmacol Exp Ther 238: $1-7$.

Carroll ME, Morgan AD, Campbell UC, Lynch WJ, Dess NK (2002). Influence of estrogen in the acquisition of intravenously selfadministration in rats selectively bred for differential saccharin intake: phenotype and sex differences. Psychopharmacology 161: 304-313.

Chin J, Sternin O, Wu HB, Burrell S, Lu D, Jenab S et al (2002). Endogenous gonadal hormones modulate behavioral and neurochemical responses to acute and chronic cocaine administration. Brain Res 945: 123-130.

Chin J, Sternin O, Wu HB, Fletcher H, Perrotti LI, Jenab S et al (2001). Sex differences in cocaine-induced behavioral sensitization. Cell Mol Biol 47: 1089-1095.

Coffey SF, Saladin ME, Drobes DJ, Brady KT, Dansky BS, Kilpatrick DG (2002). Trauma and substance cue reactivity in individuals with comorbid posttraumatic stress disorder and cocaine or alcohol dependence. Drug Alcohol Depend 65: 115-127.

Comer SD, Lac ST, Wyvell CL, Curtis LK, Carroll ME (1995). Food deprivation affects extinction and reinstatement of responding in rats. Psychopharmacology 121: 150-157.

Covington III HE, Miczek KA (2001). Repeated social-defeat stress, cocaine or morphine. Effects on behavioral sensitization and intravenous cocaine self-administration 'binges'. Psychopharmacology 158: 388-398.

Elman I, Karlsgodt KH, Gastfriend DR (2001). Gender differences in cocaine craving among non-treatment-seeking individuals with cocaine dependence. Am J Drug Alcohol Abuse 27: 193-202.

Erb S, Shaham Y, Stewart J (1998). The role of corticotropinreleasing factor and corticosterone in stress- and cocaineinduced relapse to cocaine seeking in rats. $J$ Neurosci 18: 5529-5536.

Evans SM, Haney M, Fischman MW, Foltin RW (1999). Limited sex differences in response to 'binge' smoked cocaine use in humans. Neuropsychopharmacologoy 21: 445-454.

Forgie ML, Stewart J (1993). Sex differences in amphetamineinduced locomotor activity in adult rats: role of testosterone exposure in the neonatal period. Pharmacol Biochem Behav 46: 637-645.

Forgie ML, Stewart J (1994). Sex differences in the locomotoractivating effects of amphetamine: role of circulating testosterone in adulthood. Physiol Behav 55: 639-644.

Glick SD, Hinds PA (1984). Sex differences in sensitization to cocaine-induced rotation. Eur J Pharmacol 99: 119-121.

Goeders NE (2002). Stress and cocaine addiction. J Pharmacol Exp Ther 301: 785-789.

Goeders NE, Guerin GF (1994). Non-contingent electric footshock facilitates the acquisition of intravenous cocaine self-administration in rats. Psychopharmacology 114: 63-70.
Goeders NE, Guerin GF (1996). Role of corticosterone in intravenous cocaine self-administration in rats. Neuroendocrinology 64: 337-348.

Grimm JW, Hope BT, Wise RA, Shaham Y (2001). Neuroadaptation. Incubation of cocaine craving after withdrawal. Nature 412: 141-142.

Haney M, Castanon N, Cador M, Le Moal M, Mormede P (1994). Cocaine sensitivity in Roman High and Low Avoidance rats is modulated by sex and gonadal hormone status. Brain Res $\mathbf{6 4 5}$ 179-185.

Haney M, Maccari S, Le Moal M, Simon H, Piazza PV (1995). Social stress increases the acquisition of cocaine self-administration in male and female rats. Brain Res 698: 46-52.

Howes SR, Dalley JW, Morrison CH, Robbins TW, Everitt BJ (2000). Leftward shift in the acquisition of cocaine selfadministration in isolation-reared rats: relationship to extracellular levels of dopamine, serotonin and glutamate in the nucleus accumbens and amygdala-striatal FOS expression. Psychopharmacology 151: 55-63.

$\mathrm{Hu}$ M, Becker JB (2003). Effects of sex and estrogen on behavioral sensitization to cocaine in rats. J Neurosci 23: 693-699.

$\mathrm{Hu}$ M, Crombag HS, Robinson TE, Becker JB (2004). Biological basis of sex differences in the propensity to self-administer cocaine. Neuropsychopharmacology 29: 81-85.

Jentsch JD, Taylor JR (1999). Impulsivity resulting from frontostriatal dysfunction in drug abuse: implications for the control of behavior by reward-related stimuli. Psychopharmacology 146: 373-390.

Kehoe P, Bronzino JD (1999). Neonatal stress alters LTP in freely moving male and female adult rats. Hippocampus 9: 651-658.

Kehoe P, Shoemaker WJ, Triano L, Callahan M, Rappolt G (1998). Adult rats stressed as neonates show exaggerated behavioral responses to both pharmacological and environmental challenges. Behav Neurosci 112: 116-125.

Kosten TA, Miserendino MJ, Kehoe P (2000). Enhanced acquisition of cocaine self-administration in adult rats with neonatal isolation stress experience. Brain Res 875: 44-50.

Kosten TA, Sanchez H, Zhang XY, Kehoe P (2004). Neonatal isolation enhances acquisition of cocaine self-administration and food responding in female rats. Behav Brain Res 151: 137149.

Kosten TR, Kosten TA, McDougle CJ, Hameedi FA, McCance EF et al (1996). Gender differences in response to intranasal cocaine administration to humans. Biol Psychiatry 39: 147-148.

Kuhn C, Francis R (1997). Gender difference in cocaine-induced HPA axis activation. Neuropsychopharmacology 16: 399-407.

Levine S (2002). Regulation of the hypothalamic-pituitary-adrenal axis in the neonatal rat: the role of maternal behavior. Neurotoxicol Res 4: 557-564.

Lu L, Shepard JD, Scott Hall F, Shaham Y (2003). Effect of environmental stressors on opiate and psychostimulant reinforcement, reinstatement and discrimination in rats: a review. Neurosci Biobehav Rev 27: 457-491.

Lynch WJ, Arizzi MN, Carroll ME (2000). Effects of sex and the estrous cycle on regulation of intravenously self-administered cocaine in rats. Psychopharmacology 152: 132-139.

Lynch WJ, Carroll ME (1999). Sex differences in the acquisition of intravenously self-administered cocaine and heroin in rats. Psychopharmacology 144: 77-82.

Lynch WJ, Carroll ME (2000). Reinstatement of cocaine selfadministration in rats: sex differences. Psychopharmacology 148: 196-200.

Lynch WJ, Roberts DCS (2004). Effects of cocaine self-administration on food-reinforced responding using a discrete trial procedure in rats. Neuropsychopharmacology 29: 669-675.

Lynch WJ, Roth ME, Carroll ME (2002). Biological basis of sex differences in drug abuse: preclinical and clinical studies. Psychopharmacology 164: 121-137. 
Lynch WJ, Roth ME, Mickelberg JL, Carroll ME (2001). Role of estrogen in the acquisition of intravenously self-administered cocaine in female rats. Pharmacol Biochem Behav 68: 641-646.

Lynch WJ, Taylor JR (2004). Sex differences in the behavioral effects of 24-h/day access to cocaine under a discrete trial procedure. Neuropsychopharmacology 29: 943-951.

Marinelli M, Piazza PV (2002). Interaction between glucocorticoid hormones, stress and psychostimulant drugs. Eur J Neurosci 16: 387-394.

Matthews K, Robbins TW, Everitt BJ, Caine SB (1999). Repeated neonatal maternal separation alters intravenous cocaine selfadministration in adult rats. Psychopharmacology 141: 123-134.

McCormick CM, Kehoe P, Kovacs S (1998). Corticosterone release in response to repeated, short episodes of neonatal isolation: evidence of sensitization. Int J Dev Neurosci 16: 175-185.

McCormick CM, Kehoe P, Mallinson K, Cecchi L, Frye CA (2002). Neonatal isolation alters stress hormone and mesolimbic dopamine release in juvenile rats. Pharmacol Biochem Behav 73: 77-85.

Meaney MJ, Mitchell JB, Aitken DH, Bhatnagar S, Bodnoff SR, Iny LJ et al (1991). The effects of neonatal handling on the development of the adrenocortical response to stress: implications for neuropathology and cognitive deficits in later life. Psychoneuroendocrinology 16: 85-103.

Mello NK, Mendelson JH (2002). Cocaine, hormones, and behavior: clinical and preclinical studies. Hormones Brain Behav 5: $665-745$.

Piazza PV, Deminiere JM, Le Moal M, Simon H (1990). Stress- and pharmacologically-induced behavioral sensitization increases vulnerability to acquisition of amphetamine self-administration. Brain Res 514: 22-26.

Robbins SJ, Ehrman RN, Childress AR, O'Brien CP (1999). Comparing levels of cocaine cue reactivity in male and female outpatients. Drug Alcohol Depend 53: 223-230.

Roberts DCS, Bennett SAL, Vickers GJ (1989). The estrous cycle affects cocaine self-administration on a progressive ratio schedule in rats. Psychopharmacology 98: 408-411.

Roberts DCS, Brebner K, Vincler M, Lynch WJ (2002). Patterns of cocaine self-administration in rats produced by various access conditions under a discrete trial procedure. Drug Alcohol Depend 67: 291-299.

Rots NY, de Jong J, Workel JO, Levine S, Cools AR, De Kloet ER (1996). Neonatal maternally deprived rats have as adults elevated basal pituitary-adrenal activity and enhanced susceptibility to apomorphine. J Neuroendocrinol 8: 501-506.

Schenk S, Lacelle G, Gorman K, Amit Z (1987). Cocaine selfadministration in rats influenced by environmental conditions: implications for the etiology of drug abuse. Neurosci Lett 81: 227-231.
Schmidt M, Enthoven L, van Woezik JH, Levine S, de Kloet ER, Oitzl MS (2004). The dynamics of the hypothalamic-pituitaryadrenal axis during maternal deprivation. J Neuroendocrinol 16: 52-57.

Sell SL, Scalzitti JM, Thomas ML, Cunningham KA (2000). Influence of ovarian hormones and estrous cycle on the behavioral response to cocaine in female rats. J Pharmacol Exp Ther 293: 879-886.

Shalev U, Marinelli M, Baumann MH, Piazza PV, Shaham Y (2003). The role of corticosterone in food deprivation-induced reinstatement of cocaine seeking in the rat. Psychopharmacology 168: $170-176$.

Sinha R (2001). How does stress increase risk of drug abuse and relapse? Psychopharmacology 158: 343-359.

Sinha R, Catapano D, O’Malley SS (1999). Stress-induced craving and stress response in cocaine dependent individuals. Psychopharmacology 142: 343-351.

Sinha R, Fuse T, Aubin LR, O'Malley SS (2000). Psychological stress, drug-related cues and cocaine craving. Psychopharmaco$\log y$ 152: $140-148$.

Sinha R, Talih M, Malison R, Cooney N, Anderson GM, Kreek MJ (2003). Hypothalamic-pituitary-adrenal axis and sympathoadreno-medullary responses during stress-induced and drug cue-induced cocaine craving states. Psychopharmacology 170: $62-72$.

Sircar R, Kim D (1999). Female gonadal hormones differentially modulate cocaine-induced behavioral sensitization in Fischer, Lewis, and Spraque-Dawley rats. J Pharmacol Exp Ther 289: 54-65.

Sofuoglu M, Dudish-Poulsen S, Nelson D, Pentel PR, Hatsukami DK (1999). Sex and menstrual cycle differences in the subjective effects from smoked cocaine in humans. Exp Clin Psychopharmacol 7: 274-283.

Substance Abuse and Mental Health Services Administration (2001). Summary of Findings from the 2000 National Household Survey on Drug Abuse, Office of Applied Studies, NHSDA Series H-13, DHHS Publication No. (SMA) 01-3549, Rockville, MD.

Tidey JW, Miczek KA (1997). Acquisition of cocaine selfadministration after social stress: role of accumbens dopamine. Psychopharmacology 130: 203-212.

Walker QD, Cabassa J, Kaplan KA, Li ST, Haroon J, Spohr HA et al (2001a). Sex differences in cocaine-stimulated motor behavior: disparate effects of gonadectomy. Neuropsychopharmacology 25: 118-130.

Walker QD, Francis R, Cabassa J, Kuhn CM (2001b). Effect of ovarian hormones and estrous cycle on stimulation of the hypothalamo-pituitary-adrenal axis by cocaine. J Pharmacol Exp Ther 297: 291-298. 